\title{
NIF Small Optics Laser Damage Test Specifications
}

\author{
L. Sheehan
}

April 12, 1998

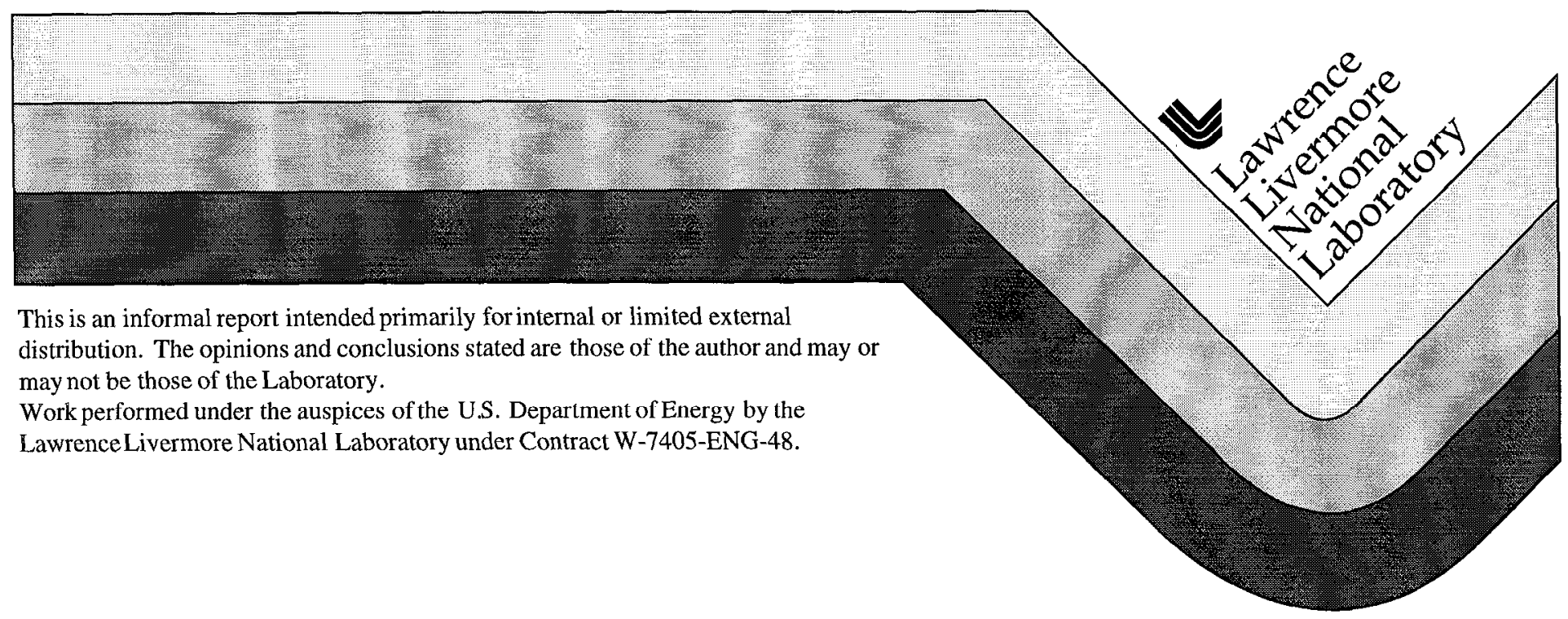




\section{DISCLAIMER}

This document was prepared as an account of work sponsored by an agency of the United States Government. Neither the United States Government nor the University of California nor any of their employees, makes any warranty, express or implied, or assumes any legal liability or responsibility for the accuracy, completencss, or uscfulness of any information, apparatus, product, or process disclosed, or represents that its use would not infringe privately owned rights. Reference herein to any specific commercial product, process, or service by trade name, trademark, manufacturer, or otherwise, does not necessarily constitute or imply its endorsement, recommendation, or favoring by the United States Government or the University of California. The views and opinions of authors expressed herein do not necessarily state or reflect those of the United States Government or the University of California, and shall not be used for advertising or product endorsement purposes.

This report has been reproduced directly from the best available copy

Available to DOE and DOE contractors from the Office of Scientific and Technical Information

P.O. Box 62, Oak Ridge, TN 37831

Prices available from (423) 576-8401

Available to the public from the National Technical Information Service

U.S. Department of Commerce 5285 Port Royal Rd.

Springfield, VA 22161 
April 12, 1998

NIF-0017738

WBS 1.6.1

To Whom It May Concern:

RE: NIF small optics laser damage test specifications

\subsection{Introduction:}

The Laser Damage Group is currently conducting tests on small optics samples supplied for initial evaluation of potential NIF suppliers. This document is meant to define the specification of laser-induced damage for small optics and the test methods used to collect the data. A rating system which will be applied for vendor selection is presented.

\subsection{Damage testing procedure:}

The systems and procedures for damage measurements at LLNL are well documented ${ }^{(1-3)}$. We are currently entering into initial phases of the NIF Small Optics vendor selection. The small optics testing is specific enough to warrant some further explanation. The raster scanning method is applied to allow for the testing of a significant amount of area. Sampling a large area increases the confidence in the optics performance rating. This test may at times be supplemented by $\mathrm{R}: 1$ mapping which is covered in section 5.0 .

\subsection{Raster scanning}

The raster scanning method employs a millimeter scale guassian beam through which the optic is scanned. This is shown graphically in Fig. 1. After each pulse the gaussian beam position is stepped a distance $\Delta(\mathrm{f} \%)$ in the $\mathrm{x}$ and $\mathrm{y}$ dimension, where $\Delta(\mathrm{f} \%)$ is the diameter of the beam at $f \%$ of the peak fluence. $\Delta(90 \%)$ is typically $150-250 \mu \mathrm{m}$. For a standard test a $1 \mathrm{~cm}^{2}$ area is scanned at an initial fluence specified by the requestor. For a $200 \mu \mathrm{m} \Delta(90 \%)$ beam size, 2500 sites are tested in that $1 \mathrm{~cm}^{2}$ area. The fluence is then increased in $3 \mathrm{~J} / \mathrm{cm}^{2}$ increments until catastrophic failure is reached. This tluence increment was chosen in order to provide a well resolved value. The increment can be changed upon request if necessary. It should be noted that the raster scanning process has the ability to condition certain optical malerials (parlicularly dielectric coatings and KDP crystals). The damage performance of the rasterscanned part should therefore be considered the conditioned performance. Unconditioned performance could potentially be lower.

There are two primary systems which will be used for the NIF small optics testing; Chameleon and the Automated Damage Test (ADT) facility. Chameleon is a $3 \mathrm{~ns}$ laser operating at $1064 \mathrm{~nm}$. The ADT operates at $355 \mathrm{~nm}$ at a $7.5 \mathrm{~ns}$ pulselength. Both systems employ a scatter based diagnostic for initial detection of damage. This diagnostic has a detection limit of 20-40 $\mu \mathrm{m}$. Damage is also observed by the operator between each fluence scan using a bright white light source. Operators can typically detect damage greater than $50 \mu \mathrm{m}$ using this technique. Plasma emission from the sample surface may also be noted, but will not be used to determine the qualification fluence. 


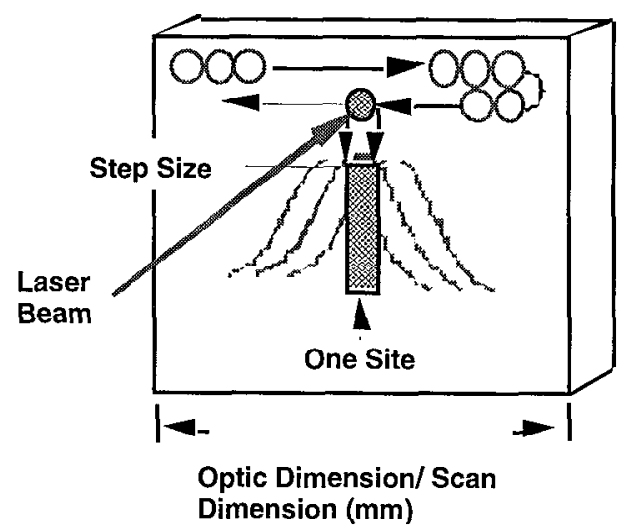

Fig. 1 Raster scanning entails translating the test area through a pulsed laser beam at a velocity such that the pulses are overlapped by a user defined amount.

\subsection{Fluence determination}

The damage performance is reported as a function of fluence in $\mathrm{J} / \mathrm{cm}^{2}$. The fluence is determined using a commercial beam profiling system and represents the peak fluence in the beam as viewed at zero degrees incidence. Further explanation of the fluence measurement can also be found in other references ${ }^{(1)}$. Note that the two damage test facilities have differing pulse lengths. The damage thresholds of bulk materials or bare surfaces can be scaled with pulse length by $\tau^{0.5}$. Coatings are scaled with pulse length by $\tau^{0.35}$.

\subsection{Determination of qualification level:}

The NIF Small Optics Group has asked that the vendor performance be binned according to the component tested and the fluences it is qualified to transport. There are three ratings; 1) qualified, 2) probable, and 3) fail.

Qualified means that up to the specified fluence, the optic showed no signs of damage. Probable means that at the specified fluence one or more of the following occurs; 1) change in the scatter above the noise limit and verified to be damage by microscopy, 2) visible pinpoint damage observed by the operator which is less than $100 \mu \mathrm{m}$, does not grow, and occurs in less than $1 \%$ of the sites. The reason for the probable qualification is to provide the Small Optics Group with alternatives for high fluence components, with a quantified amount of risk. The final category of fail is indicated if, at the specified fluence, one or more of the following occurs 1) pinpoint damage at more than $1 \%$ of the sites, 2) pinpoint damage larger than $100 \mu \mathrm{m}$ or, 3) damage which indicates growth upon further illumination (considered to be catastrophic damage).

Note that there is a $+/-15 \%$ crror tolcrance in the mcasurcment of fluence on the damage test system. In the case where the sequential scan fluences are within $15 \%$ of each other, the qualification fluence should be that of the lower scan.

\subsection{Example of vendor results and qualification:}

A representative example of a recently tested sample is shown in Table 1. This generic example shows the qualification level at the right. The damage observation information is included so that the NIF Small Optics team can understand the risk if used in the probable range. In this case at $24 \mathrm{~J} / \mathrm{cm}^{2}$ there were three $50 \mu \mathrm{m}$, damage sites which meets the criteria for probable. Also note in this example that the difference between the qualified fluence and the probable fluence is less than the $15 \%$ error of the fluence. In this case the lower fluence value of $21 \mathrm{~J} / \mathrm{cm}^{2} \mathrm{should}$ be used as the maximum qualified fluence.

Table 1 Example of raster scan results and qualifications

\begin{tabular}{|l|l|l|l|}
\hline Scan \# & Fluence J/cm ${ }^{2}$ & Damage observations & NIF Small Optics Qualification \\
\hline 1 & 12.0 & no visible damage & Qualified \\
\hline 2 & 15.0 & no visible damage & Qualified \\
\hline 3 & 18.0 & 3 to 4 small plasmas, no visible damage & Qualified \\
\hline 4 & 21.0 & 3 to 6 small plasmas, no visible damage & Qualified \\
\hline 5 & 24.0 & 3,50 m damage sites & Probable \\
\hline 6 & 27.0 & catastrophic damage & Failed \\
\hline
\end{tabular}




\subsection{R:1 Mapping}

The automated R:1 mapping method provides a damage threshold at each site tested. The advantages of this test method have been well documented in recent years ${ }^{(4-6)}$. The technique is applied where comparison of manufacturing processes or vendors is needed. It will not be used for qualification purposes.

The R:1 threshold is determined by ramping the fluence in a continuous ramp at the lasers repetition rate. The ramp has a defined starting and ending fluence and fluence increment step. During the ramp sequence, a scatter diagnostic is used to detect laser induced changes on the surface of the material under test. Upon the detection of a change in scatter the laser is shuttered and the fluence at which damage occurred is logged. This process is shown graphically in Fig. 2. Because of the fluence ramp, this test should also be considered a conditioned measurement. After the threshold is determined at a site the sample is then translated a defined distance to the next site. This is repeated for a statistically significant number of sites, usually between 16 and 100, depending on the sample size and the purpose of the test.

The damage thresholds of the individual sites are plotted as a cumulative damage probability. The highest measured damage threshold is the point at which there is a $100 \%$ probability of damage at any given site. An example plot is shown in Fig. 3. Test A consisted of a 64 site test. Test B was a 16 site test 6 weeks later. On average there is only a $2 \%$ difference in the damage measurements. The repeatability of the $\mathrm{R}: 1$ mapping measurement on average allows the routine comparison of samples with variations as small as $5 \%$. For other types of measurements the threshold can vary by $+/-15 \%$ on average. As the number of sites in the test is decreased the statistical quality of the high and low fluence tails of the distribution degrades (Test B in Fig. 3). The raster scan test provides more reliable data at the low-fluence end of the distribution.

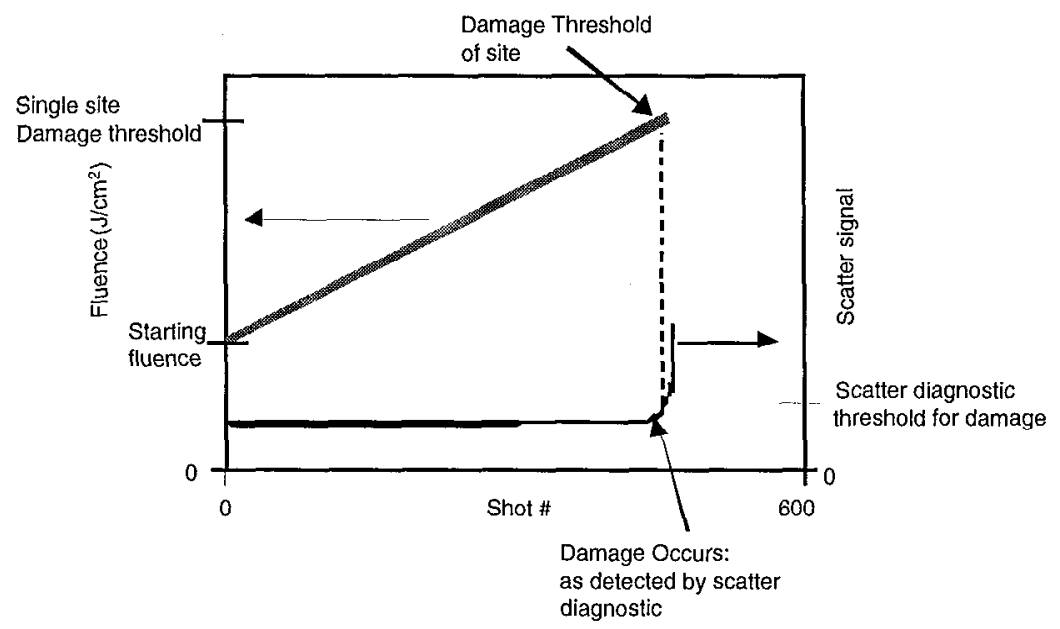

Fig. 2 R:1 testing method uses a fluence ramp and damage detection via a scatter diagnostic for determination of a damage threshold at each site tested. 


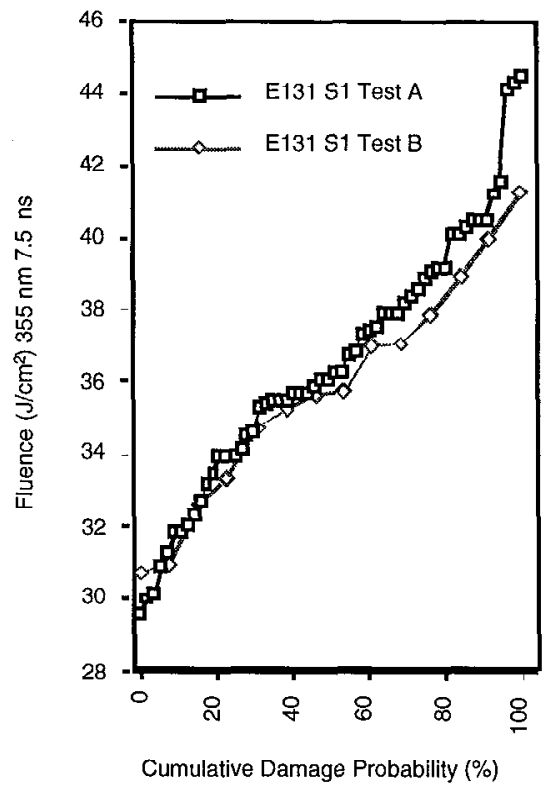

Fig. 3 Two damage probability curves measured on the same sample, using the R:1 mapping test. Test A examined 64 sites. Test B examined 16 sites and was performed six weeks after the first test. The agreement between the curves is good except at the high and low fluences where large numbers of sites must be tested to obtain good statistics.

\title{
6.0 Conclusions:
}

Presented here is the plan for qualification of NIF small optics vendors based on laser damage performance. The raster scan test method was chosen in order to provide for testing of significant areas of the samples. The vendor performance at a given fluence is categorized as either "qualified", "probable", or "fail", depending on the level of damage observed. This binning system allows a conservative stance for qualification, while providing some insight into lever of risk associated with a lowering on the specifications. The R:1 mapping technique is reserved in cases where comparisons, not qualifications are needed. Once suppliers are selected, an less intensive pass/fail test will be instituted for production optics.

\subsection{References:}

1) Sheehan, L., et.al., "Automated Damage Test Facilities for Materials Development and Production Optic Quality Assurance at Lawrence Livermore National Laboratory", Laser Induced Damage in Optical Materials: 1998, this proceedings.

2) Sheehan, L., et.al., "Large area conditioning of optics for high-power laser systems", Laser Induced Damage in Optical Materials: 1993, SPIE Vol. 2114, pp. 559-568, 1994.

3) Schwartz, S., et.al. "Vendor-based laser damage metrology equipment supporting the National Ignition Facility", Solid State Lasers for Applications to Inertial Confinement Fusion: 1998, this proceedings.

4) Hue, J. et.al., "R-on-1 automatic mapping: a new tool for laser damage testing", Laser Induced Damage in Optical Materials: 1995, SPIE Vol. 2714, pp. 90-101, 1996.

5) Runkel, M., et. al., "The effect of impurities and stress on the damage distributions of rapidly grown KDP crystals", Laser Induced Damage in Optical Materials: 1997, SPIE Vol. 3244, pp. 211-222, 1998.

6) Hue, J. et.al., "Automatic YAG damage test benches: additional possibilities", Laser Induced Damage in Optical Materials: 1998, this proceedings.

\author{
Lynn Sheehan \\ Damage Group Leader
}

